THURSDAY, APRIL II, I872

\section{NEWSPAPER SCIENCE}

J HETHER some knowledge of Science or some love for scientific truth will ever penetrate the masses, may well be questioned when we read such an article as the following, which appeared in the daily paper boasting the largest circulation in the world, and which we reprint almost entire as a curiosity of newspaper literature :-

"What is a Joule?-or who is he, if a Joule is a human being, and not a vegetable-a weapon of offence, or something to drink, or a Phantom? And if Joule be human, why did he not consider that human reason is fallible, and human patience exhaustible, when he penned, or got somebody else to pen, a maddening article which has appeared in the Nantical Magazine, from which we gather that the transformations of energy are in their nature similar to the operations of commerce; but with this difference, that in thermodynamics the relative values never vary. This, it seems, is the universal theorem of a Joule; and a red-hot poker must always bear the same relation to sixpence as the contents of a tea-kettle at boiling point bear to a five-pound note. . . . Under the new dispensation the sovereign, 'to which all other forms of energy can be referred,' is to be an unit of heat. On the obverse is stamped 'Joule's equivalent,' and on the other side is inscribed 772 foot-pounds. One unit of heat is the amount required to raise the temperature of one pound of water one degree, and the equivalent for this coin is 772 foot-pounds of work-that is, the work required to be expended to raise one pound weight 772 feet. . . But what is the new 'Joule's equivalent' to be made of ?-cobwebs, leather, or fresh butter? - and who wants to raise a pound weight 772 feet? As a problem of proportion, the theory is, of course, philosophical enough ; but it would be just as easy to fix a unit of cold as well as a unit of heat; and, under any circumstances, until Joule comes into the open and tells us who he is, what he means, and when his equivalents are to be put into circulation, society, we fear, will decline to recognise a sovereign as a Joule, or thirty shillings as a Joule and a half."

Now, with the mental condition of the man who could pen such an article as this we have nothing to do; he may go on writing according to his lights every day of the week, and no one but his own friends need interfere to stop him. But there are one or two considerations which arise from the perusal of it not without their importance.

In the first place, bearing in mind the contempt for Science so often apparent in the public utterances of men of high calibre-instances occur to us as we write, and probably will to our readers, of men of the highest culture in literature or art, who never allude to scientific work or to scientific teachers without a scarcely disguised sneer at the inferior part which they play in the national economy - we may, after all, be content that Science is alluded to at all in a paper possessing so large a circulation. The next consideration is one to which we attach the highest importance.

Surely it is now time that scientific men themselves should take a little more trouble than they do-we know it is asking a good deal from them-in the matter of bringing their own work, and the importance of it to the community, before such audiences as the daily papers afford. Were they to do this, the labours of our great VOL. v. scientific teachers-our Huxleys, Tyndalls, and Carpenters-would be enormously lightened. If we hear of an attendance of several thousands at a penny lecture by Huxley at Manchester, or a Sunday afternoon lecture in St. George's Hall by Carpenter, we fancy a love of science is spreading with rapid strides; but the fact is that the strides are not so rapid as they might be, because the labourers on whom progress depends are so few and the area of their lecture work is restricted, whereas many newspapers, on the other hand, number their readers by hundreds of thousands. Until scientific men do this, we must be content with the present state of things. It is in no spirit of invidious comparison that we may remind our readers of the frequent extracts which appear in our columns from Harper's Weekly, a political and general paper of very large circulation in the United States, the scientific department of which, containing information of the highest value, is cdited by one of the most eminent scientific men of America. But what is the present state of things with us? In the main it is one in which the public is informed of scientific work by others than the doers of the work; and the labour of classifying these writers is not difficult.

In the first place we have, we are thankful to say, a small though gradually increasing number whose labour's leave nothing to be desired, who, being men of scientific culture themselves, take a pleasure in their work, and to whom the friends of Science in this country cannot be too grateful. As an illustration of the labours of this class of writers, designed to present to the non-scientific public an account of remarkable scientific phenomena, in popular and yet accurate language, we may refer to one of the most recent publications of this class, an article entitled "A Voyage to the Sun" in the March number of the Cornhill Magazine, which we commend to the notice of all aspirants after scientifico-literary fame. The play of fancy which invests with an attractive grace a subject that would appear dry to many, is combined with a happy art of describing scientific phenomena in clear and exact language, in a manner that we have seldom seen equalled. It is impossible to overrate the labours of these gentlemen in the present condition of Science in England.

Secondly, we have a still larger class where the intention is good, but in which the culture, scientific and otherwise, is not so high. In the writings of these Science is apt to run wild: accuracy gives place to imagery, and the would-be learners, after an hour's attempt at gaining knowledge, rise from it, knowing rather less than they did before, and looking upon Science as a fearful and wonderful thing with which the less they have to do the better.

We have next a third class, composed of writers as widely different as the poles, but we place them together because the harm they both do is incalculable. The writer who is anxious to know what a "Joule" is may be taken as the type of one division. Grossly ignorant of all kinds of Science, it is nothing to him that he should bring it into discredit; he is doubtless paid for his work, and we need say no more about him. In the second division we find sometimes high culture, but the writing is not written for Science' sake. It is entirely a personal affair. The advancement of Science gives way to that of the individual and his friends, and any subject written upon is seen through a fog of personality and advertisement. 
On the whole we prefer the author of "What is a Joule?" to such a man as this, because we believe he does less harm, and is less likely to mislead "able editors."

There is one grain of comfort even in the imbecilities and inanities of would-be humorous writers in newspapers, that at least they have woke up to the idea that a scientific discovery is worth laughing at. This is a step gained. Twenty years ago, even ten years ago, the name of even so distinguished a scientist as Dr. Joule would have been utterly unknown to the herd of newspaper writers. We must be thankful for even this much; and look hopefully forward to the good day coming when Science will take her place by the side of her sisters, Art and Literature, as equally deserving of popular culture.

\section{GRISEBACH'S VEGETATION OF THE GLOBE}

Die Vegetation der Erde nach ihrer klimatischen Anordnung: ein Abriss der vergleichenden Geographie der Pfanzen; von A. Grisebach. 2 vol. (Leipzig : Engelmann, 1872.$)$

THIS important contribution to a branch of the science which, since the publication of A. de Candolle's "Géographie Botanique" and the promulgation of the Darwinian theories, has been daily acquiring greater value in the minds of philosophical naturalists, is the result of long study and persevering accumulation of data on the part of the learned author. Prof. Grisebach had already, in the "Linnæa" for 1838 , given his. first views on the limitation of natural floras by climatological influences; and since 1840 he has, in his periodical reports on the progress of geographical botany, entered more or less into the principles and conclusions which he has successively entertained or matured. He now supplies us in these volumes with a methodical digest of the facts he has collected, and of the conclusions he would draw from them. The result is a rich store of materials, which future investigators of the subject must necessarily have recourse to, and the arrangement adopted is perhaps the one best calculated to illustrate that branch of it which is more especially indicated by the title, the influence of climate and physical conditions on the stations and areas of species. But to the general naturalist the value of the work as a book of reference is much diminished by two great deficiencies; there is no summary of the conclusions he would draw from the facts he has detailed, and no index to enable the reader to turn to any individual fact, argument, or deduction, which may have struck him in the perusal of above $\mathrm{I}, 200$ closely printed pages.

The question of the Origin of Species is not entered into, for the author believes that acknowledged facts prove nothing more than the production of varieties through climatological or other influences, but that " however interesting speculations on the genetic connections of organisms may appear, we abandon the territory of facts when we indulge in conjectures on the origin of more widely separated forms or races, of species, genera, or families of plants or animals." "That the limits between a species and a variety are not always to be strictly defined, is no reason," he observes,." why we should ascribe to both an identical process of formation, or that we should regard the forces by which the gradual variations of forms are effected as the only ones by which the multiplicity of nature has been produced."

As far as we have been able to collect the professor's views, his idea seems to be that, whatever may have been its origin, every species now existing on the globe was at some given (or uncertain) time "produced" in one particular spot, the centre of the species, from whence it has, from the natural tendency to multiplication inherent in every organised race, spread in every direction where its progress has not been checked by extraneous causes, generally by climatological or other physical opposing influences, sometimes by the mere struggle with competing races. Wherever a considerable number of species appear to have had their centres within a limited area, that area is termed a centre of vegetation (Vegetations-centrum); where the migration of plants from one or more centres is limited by physical obstructions, by mountain chains, seas, adverse climate, \&c., the space thus enclosed is the province (Gebiet) of a natural flora. For the "centres of vegetation," the author had originally made use of the term "centres of creation" (Schöpfungs-centren), which he has now abandoned on account of the objections made to it as expressing some definite process of production. "I, at least," he adds, "under an act of creation, never understood anything else than the operation of certain laws of nature, the further knowledge of which is, as yet, withheld from us. Bentham prefers for the term 'centres of vegetation' that of 'areas of preservation,' when they remain in their original state, as in oceanic is!ands, a mode of expression to which we might well be reconciled" (p. 523). With regard to the term Gebiet, the natural translation would be region, but in this instance, with the facility enjoyed by Germans of adopting words of foreign languages, the word "Region" is made use of for areas limited by altitude within the Gebiet.

The twenty-four botanical provinces of natural floras which Grisebach had already sketched out in Petermann's Mittheilungen are here necessarily taken in detail, investigating under each one-(I) the climate ; (2) the prevailing plant-forms; (3) the prevailing plant-formations; (4) the regions, chiefly as to altitude ; and (5) the centres of vegetation included in the province. For the "plant-forms" he has carried out a classification founded on that of Humboldt, distributing plants under seven heads-(I) woody plants; (2) succulent plants; (3) climbers ; (4) epiphytes; (5) herbs; (6) grasses-including sedges, reeds; \&c. ; (7) cellular plants : each one subdivided into minor groups. The "plant-formations" are tracts of country whose general aspect is characterised by their vegetation, such as forests, heaths, scrubs, deserts, cultivated tracts, \&c.

The two provinces worked out with the greatest care, and for which the materials here collected are perhaps the most deserving of study, as being the most ample, and in both cases checked by the personal experience of the author, are the Forest-province (Waldgebiet) of the eastern continent (the greater part of Europe and temperate Asia), and the Mediterranean region; the one characterised by its vast uniformity, the other by its broken diversity; in both of which the complicated influences of climate, configuration, and soil, have been more carefully observed, recorded, and studied, than in any other quarter of the globe. The Mediterranean region is particularly instruc- 